\title{
Supine effect of passive cycling movement induces vagal withdrawal
}

\author{
Daisuke Fujita, PhD, RPT ${ }^{1)^{*}}$, Kousei Kubo, MS, RPT ${ }^{2)}$, Daisuke Takagi, PhD, RPT ${ }^{1}$, \\ YuUSUKE NishidA, PhD, RPT ${ }^{3)}$ \\ 1) Department of Physical Therapy, Health Science University: Minamitsurugun, Yamanashi, Japan \\ 2) Department of Rehabilitation, Iwata City Hospital, Japan \\ 3) Department of Physical Therapy, Seirei Christopher Univesrity, Japan
}

\begin{abstract}
Purpose] The purpose of this study was to examine changes in vagal tone during passive exercise while supine. [Subjects and Methods] Eleven healthy males lay supine for $5 \mathrm{~min}$ and then performed passive cycling for $10 \mathrm{~min}$ using a passive cycling machine. The lower legs moved through a range of motion defined by $90^{\circ}$ and $180^{\circ}$ knee joint angles at $60 \mathrm{rpm}$. Respiratory rates were maintained at $0.25 \mathrm{~Hz}$ to elicit respiratory sinus arrhythmia. Heart rate variability was analyzed using the time domain analysis, as the root mean squared standard differences between adjacent R-R intervals (rMSSD), and spectrum domain analysis of the high frequency (HF) component. [Results] Compared to rest, passive cycling decreased rMSSD (rest, $66.6 \pm 92.6 \mathrm{~ms}$; passive exercise, $53.5 \pm 32.5 \mathrm{~ms}$ ). However, no significant changes in HR or HF were observed (rest, $68.2 \pm 6.9 \mathrm{bpm}, 65.6 \pm 12.0$ n.u.; passive exercise, $70.2 \pm 7.2 \mathrm{bpm}, 67.9 \pm 10.0$ n.u.). [Conclusion] These results suggest that passive exercise decreases rMMSD through supine-stimulated mechanoreceptors with no effect on HR or HF. Therefore, rMSSD is not affected by hydrostatic pressure during passive cycling in the supine position.

Key words: Passive cycling movement, Supine position, Vagal tone
\end{abstract}

(This article was submitted Jul. 1, 2015, and was accepted Aug. 5, 2015)

\section{INTRODUCTION}

Stimulation of mechanoreceptors during passive cycling induces increases in heart rate (HR) and stroke volume (SV) in humans ${ }^{1,2)}$. These changes occur in passive exercise, but moderate intensity knee extension exercises do not induce sympathetic nerve activity ${ }^{3)}$. Moreover, sympathetic nerve activation is unlikely to occur during passive cycling, particularly at $\mathrm{HR}<100 \mathrm{bpm}^{4}$. According to this paradigm, the neural components most likely to be responsible for increases in HR during passive cycling are afferent feedback pathways from group III mechanoreceptors and subsequent vagal withdrawal ${ }^{5)}$. Passive exercise-induced changes in autonomic function are termed the mechanoreflex ${ }^{6}$.

A previous study ${ }^{7}$ ) suggested that the mechanoreflex contributes less to regulation of the circulatory system during exercise than other functions, such as the central command, baroreflex, and metaboreflex. However, another study reported that the mechanoreflex is occurred with overactivation of sympathetic nerves, leading to increased heart rate and systolic blood pressure in patients with heart failure compared with that in controls ${ }^{8}$. In addition, elderly indi-

*Corresponding author. Daisuke Fujita (E-mail: d-fujita@ kenkoudai.ac.jp)

C2015 The Society of Physical Therapy Science. Published by IPEC Inc. This is an open-access article distributed under the terms of the Creative Commons Attribution Non-Commercial No Derivatives (by-ncnd) License $<$ http://creativecommons.org/licenses/by-nc-nd/3.0/> . viduals have significantly smaller changes in HR and cardiac output (CO) in response to passive exercise than young individuals ${ }^{5}$, demonstrating that passive exercise-induced physiological responses are affected by aging. Thus, mechanoreflex is involved in the regulation of autonomic function in heart failure ${ }^{8)}$, muscle atrophy ${ }^{9}$, and peripheral arterial disease ${ }^{10)}$. Therefore, the evaluation of autonomic function via the mechanoreflex has clinical importance.

Previous studies have demonstrated that passive cycling induced decreases vagal tone using passive exercise models performed in the upright seated position ${ }^{1,2)}$. Postural changes affect hydrostatic pressure associated with physiological responses $^{11-13)}$. However, the effect of passive exercise in the supine position on vagal tone remains unknown.

This study investigated passive cycling movement in the supine position induces decreasing vagal tone using heart rate variability.

\section{SUBJECTS AND METHODS}

Eleven healthy males (mean age, $23.0 \pm 2.0$ years; height, $170.4 \pm 6.1 \mathrm{~cm}$; weight, $63.1 \pm 7.8 \mathrm{~kg}$ ) participated in this study. The subjects did not perform exercise for the past $24 \mathrm{~h}$ before, or consumed caffeine fort $12 \mathrm{~h}$ before the measurements. This study conformed to the Declaration of Helsinki, and informed consent was obtained from all participants in accordance with the protocol of the Ethics Committee of the Seirei Christopher University (13060).

Subjects lay supine for $5 \mathrm{~min}$. One minute prior to the start of passive cycling for $10 \mathrm{~min}$, their ankles were placed 
on the pedals and set in the straps of passive cycling movement device (Room March Pro, Yuubun Ltd., Japan). The lower legs moved through a range of motion defined of $90^{\circ}$ and $180^{\circ}$ knee joint angles at $60 \mathrm{rpm}$. Prior to the start of passive exercise and throughout the protocol, subjects were encouraged to remain passive and resist any urge to assist with leg movement.

Electrocardiography (ECG) was performed using one lead in a standard CM5 configuration, with three silver chloride monitoring electrodes placed on the chest. ECG traces were recorded at a sampling frequency of $1,000 \mathrm{~Hz}$ (Powerlab and software Chart5, AD instruments, Australia). Respiratory rates were monitered by an expired gas analyzer (AE-300S, MINATO, Japan) and maintained throughout the protocol at $0.25 \mathrm{~Hz}$, with $2 \mathrm{~s}$ exhalation and $2 \mathrm{~s}$ inhalation, to elicit the effect of respiratory sinus arrhythmia (RSA) ${ }^{14)}$.

Heart rate variability was analyzed as root mean squared standard differences between adjacent R-R intervals (rMS$\mathrm{SD})$ using measures in the time domain and spectrum domain analysis of the high frequency (HF) components, both of which provided information regarding parasympathetic heart modulation ${ }^{15)}$.

All data are presented as the mean \pm standard deviation over the average data over the 5-min rest periods and 10min passive exercise periods. rMSSD, HF, and HR were compared between rest and passive exercise using the paired $\mathrm{t}$-test. The significance of all statistical tests was accepted at values of $p<0.05$. All data are presented as mean \pm standard deviation.

\section{RESULTS}

All data are shown in Table 1. Passive exercise induced significant decreases in rMSSD (rest, $66.6 \pm 92.6 \mathrm{~ms}$; passive exercise, $53.5 \pm 32.5 \mathrm{~ms}, \mathrm{p}<0.05$ ). No significant difference in HF or HR were observed during passive exercise compared with rest (their respective values; rest, $68.2 \pm 6.9$ bpm, $65.6 \pm 12.0$ n.u.; passive exercise, $70.2 \pm 7.2 \mathrm{bpm}, 67.9$ \pm 10.0 n.u., $\mathrm{p} \geq 0.05$ ).

\section{DISCUSSION}

The present findings demonstrate that passive exercise induces decreases in rMSSD, which is an indicator of vagal tone, despite having no effect on HR or HF.

The passive exercise model used in this study allows assessment of the mechanoreflex that is independent of the effects of metaboreflex and central command ${ }^{5)}$, and does not involve muscle contractions, as confirmed by the lack of changes in electromyography signals compared with rest ${ }^{2}$.

Of the three mechanoreceptor subtypes known to exist, i.e., those responsive to muscle contraction, those responsive to stretch, and those responsive to both mechanical stimuli ${ }^{16)}$, passive limb movements are considered to predominantly stimulate stretch-responsive mechanoreceptors.

Activation of the mechanoreflex mediates cardio acceleration by reducing the excitability of the cardiac vagal motoneuron pool ${ }^{17-18)}$. Furthermore, electrically evoked static contraction and passive stretch mechanically distort type III muscle afferents and reflexively reset the baroreflex
Table 1. HR, rMSSD and HF during rest and passive cycling movement

\begin{tabular}{llc}
\hline & Rest & $\begin{array}{c}\text { Passive cycling } \\
\text { movement }\end{array}$ \\
\hline HR (bpm) & $68.2 \pm 6.9$ & $70.2 \pm 7.2$ \\
rMSSD (ms) & $66.6 \pm 38.0$ & $53.5 \pm 32.5^{*}$ \\
HF (n.u.) & $65.6 \pm 12.0$ & $67.9 \pm 10.0$ \\
\hline
\end{tabular}

Values are mean \pm SD

Significantly dirrerent from rest: $* \mathrm{p}<0.05$

neural arc to higher sympathetic nerve activity ${ }^{19)}$, resulting in increased cardiac ${ }^{17)}$ and renal ${ }^{18)}$ sympathetic traffic before the activation of the metaboreflex ${ }^{20)}$. Thus, the activation of the muscle mechanoreflex mediates vagal inhibition and sympatho excitation in the absence of a central command and the muscle metaboreflex. This shifting of sympatho vagal balance is not counteracted by the baroreflex because neural input from the muscle mechanoreflex resets the baroreflex operating point to a higher operating pressure ${ }^{19,21)}$ in a manner similar to that of the central command ${ }^{22}$.

This study found no change in HR in response to passive cycling when supine. A previous study ${ }^{23)}$ demonstrated that $\mathrm{SV}$ and mean arterial pressure are unchanged in the supine position. Therefore, $\mathrm{CO}$ is likely solely driven by transient increases in HR because the contribution of the muscle pump is reduced and the baroreflex is not invoked while supine. The lack of change in SV in the supine position can be explained by a greater central blood volume, central venous pressure, and left ventricular end-diastolic volume ${ }^{24-27)}$.

Subjects' respiratory rates were controlled because RSA is known to affect the HF components that the decrease in the respiratory rate increases the HF component without changing the mean cardiac vagal tone ${ }^{28)}$. Therefore, no significant changes in HF components were observed in response to passive exercise in the supine position. Moreover, passive cycling induced decreases in rMSSD because of vagal withdrawal in the supine position. These results from a model of passive exercise in the supine position suggest rMSSD is a more highly sensitive indicator of cardiac vagal tone than the HF component during very low intensity exercise, such as passive cycling movement.

In conclusion, passive cycling in the supine position induced decreases in vagal tone with no effect on the HF components or HR. These findings indicate rMSSD is a more sensitive indicator of the mechanoreflex during passive cycling than the measurements of the HF components.

\section{REFERENCES}

1) Nóbrega AC, Williamson JW, Friedman DB, et al.: Cardiovascular responses to active and passive cycling movements. Med Sci Sports Exerc, 1994, 26: 709-714. [Medline] [CrossRef]

2) Nurhayati Y, Boutcher SH: Cardiovascular response to passive cycle exercise. Med Sci Sports Exerc, 1998, 30: 234-238. [Medline] [CrossRef]

3) Wray DW, Fadel PJ, Keller DM, et al.: Dynamic carotid baroreflex control of the peripheral circulation during exercise in humans. J Physiol, 2004, 559: 675-684. [Medline] [CrossRef]

4) Robinson BF, Epstein SE, Beiser GD, et al.: Control of heart rate by the autonomic nervous system. Studies in man on the interrelation between baroreceptor mechanisms and exercise. Circ Res, 1966, 19: 400-411. [Medline] 
[CrossRef]

5) McDaniel J, Hayman MA, Ives S, et al.: Attenuated exercise induced hyperaemia with age: mechanistic insight from passive limb movement. J Physiol, 2010, 588: 4507-4517. [Medline] [CrossRef]

6) Vianna LC, Oliveira RB, Ramos PS, et al.: Effect of muscle mass on muscle mechanoreflex-mediated heart rate increase at the onset of dynamic exercise. Eur J Appl Physiol, 2010, 108: 429-434. [Medline] [CrossRef]

7) Nishiyasu T, Maekawa T, Sone R, et al.: Effects of rhythmic muscle compression on cardiovascular responses and muscle oxygenation at rest and during dynamic exercise. Exp Physiol, 2006, 91: 103-109. [Medline] [CrossRef]

8) Middlekauff HR, Chiu J, Hamilton MA, et al.: Muscle mechanoreceptor sensitivity in heart failure. Am J Physiol Heart Circ Physiol, 2004, 287 H1937-H1943. [Medline] [CrossRef]

9) Hayashi N, Koba S, Yoshida T: Disuse atrophy increases the muscle mechanoreflex in rats. J Appl Physiol 1985, 2005, 99: 1442-1445. [Medline] [CrossRef]

10) Muller MD, Drew RC, Blaha CA, et al.: Oxidative stress contributes to the augmented exercise pressor reflex in peripheral arterial disease patients. J Physiol, 2012, 590: 6237-6246. [Medline] [CrossRef]

11) Doufesh H, Ibrahim F, Ismail NA, et al.: Assessment of heart rates and blood pressure in different salat positions. J Phys Ther Sci, 2013, 25: 211214. [CrossRef]

12) Kim MK, Hwangbo G: Effect of position on measured lung capacity of patients with spinal cord injury. J Phys Ther Sci, 2012, 24: 655-657. [CrossRef]

13) Tsubaki A, Deguchi S, Yoneda Y: Influence of posture on respiratory function and respiratory muscle strength in normal subjects. J Phys Ther Sci, 2009, 21: 71-74. [CrossRef]

14) Hirsch JA, Bishop B: Respiratory sinus arrhythmia in humans: how breathing pattern modulates heart rate. Am J Physiol, 1981, 241: H620H629.[Medline]

15) Task Force of the European Society of Cardiology and the North American Society of Pacing and Electrophysiology: Heart rate variability: standards of measurement, physiological interpretation and clinical use. Circulation, 1996, 93: 1043-1065. [Medline] [CrossRef]

16) Gladwell VF, Coote JH: Heart rate at the onset of muscle contraction and during passive muscle stretch in humans: a role for mechanoreceptors. $\mathrm{J}$ Physiol, 2002, 540: 1095-1102. [Medline] [CrossRef]
17) Murata J, Matsukawa K: Cardiac vagal and sympathetic efferent discharges are differentially modified by stretch of skeletal muscle. Am J Physiol Heart Circ Physiol, 2001, 280: H237-H245. [Medline]

18) Matsukawa K, Wall PT, Wilson LB, et al.: Reflex responses of renal nerve activity during isometric muscle contraction in cats. Am J Physiol, 1990, 259: H1380-H1388. [Medline]

19) Yamamoto K, Kawada T, Kamiya A, et al.: Muscle mechanoreflex induces the pressor response by resetting the arterial baroreflex neural arc. Am J Physiol Heart Circ Physiol, 2004, 286: H1382-H1388. [Medline] [CrossRef]

20) Kaufman MP, Hayes SG: The exercise pressor reflex. Clin Auton Res, 2002, 12: 429-439. [Medline] [CrossRef]

21) Potts JT, Mitchell JH: Rapid resetting of carotid baroreceptor reflex by afferent input from skeletal muscle receptors. Am J Physiol, 1998, 275: H2000-H2008. [Medline]

22) DiCarlo SE, Bishop VS: Central baroreflex resetting as a means of increasing and decreasing sympathetic outflow and arterial pressure. Ann N Y Acad Sci, 2001, 940: 324-337. [Medline] [CrossRef]

23) Trinity JD, McDaniel J, Venturelli M, et al.: Impact of body position on central and peripheral hemodynamic contributions to movement-induced hyperemia: implications for rehabilitative medicine. Am J Physiol Heart Circ Physiol, 2011, 300: H1885-H1891. [Medline] [CrossRef]

24) Bevegard S, Holmgren A, Jonsson B: The effect of body position on the circulation at rest and during exercise, with special reference to the influence on the stroke volume. Acta Physiol Scand, 1960, 49: 279-298. [Medline] [CrossRef]

25) Ekelund LG: Circulatory and respiratory adaptation during prolonged exercise. Acta Physiol Scand Suppl, 1967, 292: 1-38. [Medline]

26) González-Alonso J, Mora-Rodríguez R, Coyle EF: Supine exercise restores arterial blood pressure and skin blood flow despite dehydration and hyperthermia. Am J Physiol, 1999, 277: H576-H583. [Medline]

27) Poliner LR, Dehmer GJ, Lewis SE, et al.: Left ventricular performance in normal subjects: a comparison of the responses to exercise in the upright and supine positions. Circulation, 1980, 62: 528-534. [Medline] [CrossRef]

28) Hayano J, Mukai S, Sakakibara M, et al.: Effects of respiratory interva on vagal modulation of heart rate. Am J Physiol, 1994, 267: H33-H40. [Medline] 